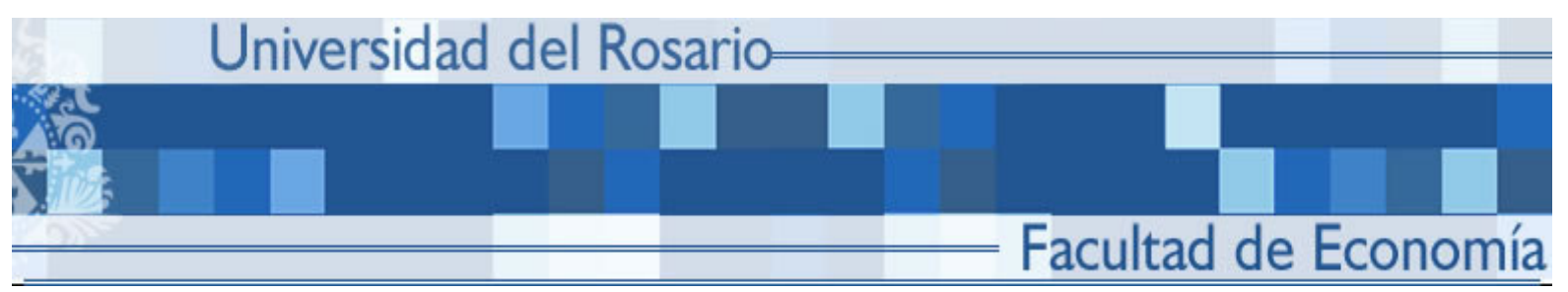

RE-MEASURING LABOR'S SHARE

Andrew T. Young

Hernando Zuleta

SERIE DOCUMENTOS DE TRABAJO

No. 36

Mayo 2008 


\title{
Re-measuring Labor's Share ${ }^{\dagger}$
}

\author{
Andrew T. Young* \\ Department of Economics \\ University of Mississippi \\ University, MS 38677 \\ atyoung@olemiss.edu \\ Tel: 6629155829 \\ Fax: 6629156943
}

\author{
Hernando Zuleta \\ Universidad del Rosario \\ Casa Pedro Fermín \\ Calle 14 \# 4 - 69
}

hernando.zuleta84@urosario.edu.co

Tel: +57 (1) 2970200

\section{JEL Codes: O11, O30, 041}

Keywords: Labor's Share, Factor Shares, Development, Biased Technical Change, Capital Intensity

Last Revision: April 2008

\footnotetext{
${ }^{\dagger}$ We wish to thank John Seater for providing very helpful suggestions based on a previous draft. Also, we thank Mun Ho for supplementing the data that was publicly available to us and for commenting on some features of that data.

* Corresponding author.
} 


\section{Introduction}

Measuring labor's share of an economy's aggregate income seems straightforward, at least in principle. Count up wage and salary income, along with the value of benefits provided to employees, and divide it by total income. However, one fundamental concept of labor's share in macroeconomic theory is not the amount of aggregate income paid out to labor. Rather, it is the share of aggregate production that is attributable to "raw" units of labor. Or, otherwise stated, it is the share of aggregate income that would have been paid to laborers if they had no accumulated stocks of human capital. ${ }^{1}$ This share corresponds to an aggregate production function parameter: the elasticity of output with respect to physical (i.e. non-augmented or raw) units of labor (Robert Solow, 1957). In this paper we estimate annual raw labor's share for the US, 1949 to 1996.

Alan Krueger (1999) provides, to our knowledge, the only other such measure for a comparable time period in the US. ${ }^{2}$ His measure is based on (Jacob) Mincerian (1974) regressions using Census data, at the level of the individual, on earnings, schooling, and work experience. ${ }^{3}$ Interpreting the intercept of such regressions as "raw" labor earnings, Krueger (1999, Table 2) finds that raw labor's share fell by over 8 percent from 1959

\footnotetext{
${ }^{1}$ The marginal product of these raw units of labor would still be a function of the existing stocks of human and physical capital, so we do not assume away the human capital stocks but, instead, divorce them from individuals as far as payments.

${ }^{2}$ This paper's title is a play on Krueger's (1999) title and, as such, recognizes the pioneering nature of that effort.

${ }^{3}$ The Census data was supplemented by Current Population Survey (CPS) data for the non-Census year, 1996.
} 
through 1996 to under 5 percent of national income. ${ }^{4}$ This is remarkable because it implies a share of national income attributable to human capital of over 70 percent $!^{5}$

Krueger's (1999, p. 50) conclusion: "Raw labor's share . . declined since 1979, which is not surprising in view of the well-documented rise in the return to education and experience in this period." ${ }^{6}$ This is certainly plausible. One interpretation is that the growth rate of the marginal productivity of human capital increased during the relevant time period. A competing - or, better, complementary - interpretation is that compensation to raw labor fell or grew slowly relative human capital's compensation. ${ }^{7}$ The approach to calculating raw labor's share pursued in this paper hopefully can lend some insight into the relative validity of these two interpretations.

Our approach differs in that, rather than estimating raw labor earnings from observations on a broad sample of workers, we use direct observations on the wage rates of uneducated and inexperienced workers. Our preferred measure of raw labor's share is considerably higher than that reported by Krueger with a high of nearly 30.9 percent in 1949 and a low of 12.4 percent in 1974 . Furthermore, unlike the Krueger measure which falls from 1979 onward, our measure rises during the later part of the sample and is over 22 percent by 1996.

\footnotetext{
${ }^{4}$ We will adopt Krueger's terminology, raw labor's share, for the remainder of the paper to distinguish the particular concept from other conceptualizations of labor's share, e.g., compensation of employees as a share of aggregate income.

${ }^{5}$ This is based on a conventionally-estimated NIPA labor's share of 76.1 percent in 1996 (Krueger, 1999 , Table1).

${ }^{6}$ The rise in the return to education has been attributed to skill-biased technical change that outpaced a growing supply of educated labor (Lawrence Katz and Kevin Murphy, 1992) and was perhaps even induced by that growing supply (Daron Acemoglu, 2002).

${ }^{7}$ This would be consistent with the claim that weakening labor market institutions - e.g. labor unions and the minimum wage - underlies the fall in labor's share. Katz and David Autor (1999), Claudia Goldin and Katz (2001), and Acemoglu (2002) review the relevant literature. For evidence and discussion of the anemic growth in the earnings of lower income groups (and its growth relative to the earnings of higher income groups) see John Willis and Julie Wroblewski (2007).
} 
This paper proceeds as follows. Section II provides an exposition of both Krueger's (1999) approach to measuring raw labor's share and the alternative approach pursued here. We describe the data of Dale W. Jorgenson and Kevin J. Stiroh (1999) and Mun S. Ho and Dale W. Jorgenson (1999) that we exploit to measure raw labor's share in Section III. In that section we also briefly describe Krueger's (1999) data for comparison's sake. Section IV presents our results, compares and contrasts them to those of Krueger (1999), and suggests possible reasons for the differences. Section V concludes with some commentary on the relative virtues of each approach and possible reasons for their different implications when brought to the data.

\section{Two Approaches to Measuring Raw Labor's Share}

Krueger (1999, p. 49) begins with the assumption that, "each worker's earnings consist of two additive components: raw labor and human capital". Based on this assumption, Krueger estimates a Mincerian earnings regression of the form,

$$
\ln \left(W_{i}\right)=b_{0}+b_{1} S_{i}+b_{2} X_{i}+b_{3} X_{i}^{2}+e_{i}
$$

where $W_{i}$ are a given worker's ( $i$ 's) annual earnings, $S_{i}$ is years of schooling, $X_{i}$ is a measure of "potential" experience (i's age minus $S_{\mathrm{i}}$ minus 6), and $e_{i}$ is an error term. Given the mean square error of the regression, $\sigma^{2}$, earnings attributable to raw labor are then computed as $W_{0}=\exp \left(b_{0}+0.5 \sigma^{2}\right)$.

While Krueger (1999, p. 49) is careful to note several caveats about this measure (e.g., the minimum wage may raise the regression intercept), it is undoubtedly an intuitive way of separating education's and experience's - taken together, human capital's 
- contributions to earnings. ${ }^{8}$ The earnings attributable to raw labor, or what "might more appropriately be called 'intercept labor'" (Krueger, 1999, p. 49), are that component of total earnings not accounted for by proxies for human capital.

Given the raw labor earnings measure, it is straightforward to approximate the share of labor income accruing to raw labor, $n W_{0} / \sum W_{i}$, where $n$ is the number of workers. Taking this share of total labor income as a fraction of national income yields a measure of raw labor's share.

In this paper we pursue an alternative approach. Rather than effectively estimate earnings accruing to raw labor, we directly observe the earnings of "raw" labor units. Krueger's approach samples workers with various levels of human capital and then attempts to control for those human capital levels in a regression. Alternatively, we identify individual workers with no (or very little) experience and schooling and use their earnings to calculate a raw wage rate. Along with a measure of total labor hours, this raw wage rate implies a raw labor's share of total income.

Both approaches to measuring raw labor's share begin with an assumption of what (roughly) constitutes a raw laborer, i.e., an adult with no formal education that has had no market employment. ${ }^{9}$ In one sense this is arbitrary. Human capital accumulation also includes all of the informal education and experiences from birth and onward. However, physical maturity seems to be important for what most would consider a baseline labor

\footnotetext{
${ }^{8}$ The minimum wage may also increase the relative share of unskilled employment, so the net effect on the share of raw labor is not clear.

${ }^{9}$ Recall that potential experience in the Krueger regression is age minus education minus 6. This implies that, e.g., that an 18 year old high school $\left(12^{\text {th }}\right.$ grade) graduate has potential experience of zero. Our baseline raw wage rate below is based on a more liberal definition of "adult", namely at least 16 years old. An alternative raw wage rate series we examine ups the minimum age considered to 18 years old.
} 
unit. So a raw labor unit is conceived of as levels of experience and education relative to the minimum that an adult would be expected to embody.

\section{Data}

We utilize the 1948 to 1996 US data set studied by Jorgenson and Stiroh (1999) which is based on an aggregate production function,

$$
Y=f(K, D, L, T),
$$

where, in real terms, $Y$ is output, $K$ the flow of capital services, $D$ is the flow of consumer durables services, $L$ is labor input, and $T$ is an index of technology. ${ }^{10}$

Capital services, $K$, are based on Bureau of Economic Analysis (BEA) investment data for various residential and non-residential structures (48 and 22 types, respectively) and producers' durable goods (35 types). Jorgenson and Stiroh (1999) calculate capital stocks using the perpetual inventory method and depreciation rates from Fraumeni (1997). Calculation of $D$ is parallel to $K$ and is based on BEA data on 13 types of consumer durable goods.

Importantly, $L$ is not a raw measure of labor input such as hours worked, $H$, but rather a constant quality index based on the methodology of Jorgenson, Frank M. Gollop, and Barbara M. Fraumeni (1987) and the work of Ho and Jorgenson (1999). ${ }^{11}$ The basic data is observations on individuals' hours worked and wages that and come from the US Census for available years and are supplemented by Consumer Population Survey (CPS) data for intervening years. Hours worked are assembled into matrices according to

\footnotetext{
${ }^{10}$ Since labor's share is calculated below as a Tornquist approximation for instantaneous labor's shares, our raw labor's share series are calculated only for 1949 to 1996.

${ }^{11}$ See Ho and Jorgenson (1999, Section 2 \& Appendix A) for details of the methodology and data.
} 
individuals' age, sex, employment class, industry and education. Matrix elements are then weighted by their average share of total labor compensation.

Using the Jorgenson and Stiroh (1999) data, conventional labor's share - what we will refer to as labor service's share - averages 0.58 and displays the familiar (roughly) horizontal trend (Figure 1). This represents labor income as a share of value-added.

Figure 1 also plots Krueger's (1999) raw labor's share which is significantly lower and falling throughout the 1980s and 1990s. These observations are based on his estimation of (1) using Census data and, for the 1997 measure, CPS data on individuals' earnings, years of schooling, and workplace experience. Estimated "intercept labor" earnings are then taken as a share of national income from the BEA.

Our calculation of raw labor's share is based on comparable (Census and CPS) data. We go into the labor matrices of Ho and Jorgenson (1999) and focus on workers who have virtually no human capital in terms of experience and educational attainment. ${ }^{12}$ Specifically, as our baseline we focus on male employees, 16 to 17 years of age, with $8^{\text {th }}$ grade education or less. ${ }^{13}$ The ages of these workers rule out any substantial on-the-job experience and their formal schooling is nil; they are actual, observable raw units of labor. For these workers we have data on compensation and hours worked, yielding a nominal compensation per hour (or wage) rate. This wage rate is then deflated using the output price index $(P Y)$ from the Jorgenson and Stiroh (1999) data to give us a real wage rate for raw labor. We then compute what would be the total wage bill if all hours

\footnotetext{
${ }^{12}$ Most of the data we use is available at Dale Jorgenson's website, http://post.economics.harvard.edu/faculty/jorgenson/data.html, and Mun Ho kindly provided additional data from the labor matrices.

${ }^{13}$ We choose to begin with male workers to avoid issues of gender discrimination and we avoid the selfemployed based on the assumption that they are perhaps, in general, exceptionally motivated and/or naturally possessing of organizational skills. Below we demonstrate that focusing on women does not alter the results in any meaningful way.
} 
worked $(H)$ were compensated at that rate. That hypothetical wage bill as a fraction of total output $(Y)$ is our baseline raw labor's share.

\section{Raw Labor's Share}

Figure 2 plots our raw labor's share as well as Krueger's (1999) measure. Our measure is in general higher, averaging just under 0.22 (Table 1; column 2). ${ }^{14}$ Also, it appears to trend upwards through the 1980s and 1990s unlike the falling Krueger measure. This feature is highlighted by the inclusion on Figure 2 of an HP-filter (smoothing parameter equal to 100) trend. If one regresses our raw labor's share series on a constant and a time trend $(T=1, \ldots, 49)$, the OLS result is,

$$
L S_{R A W}=0.274-0.002 * T,
$$

where the time trend is significant at the 1 percent level (standard error $=0.001)$. This is a statistically significant negative trend, and implies ceteris paribus almost a 10 percent decreases in raw labor's share over the sample period. However, the result is driven by the steep decreases during the 1950s and 1960s. The same regression using only data from 1970 onward yields,

$$
L S_{R A W}=0.077+0.003 * T .
$$

The time trend is again significant at the 1 percent level (standard error $=0.001)$ but is now positive implying ceteris paribus just under and 8 percent increase in raw labor's share from 1970 to 1996.

One unfortunate feature of this raw labor's share series is that is very volatile, evidenced by its standard deviation - over 2.5 times that of labor service's share. This

\footnotetext{
${ }^{14}$ The average is only slightly lower - just under 0.20 - if we consider only 1959 through 1996 , which encompasses the Krueger points displayed in the figure. As well, Krueger (1999, Table 2) also reports a value for 1939 which is the lowest of all his reported values: just under 0.10 .
} 
volatility is a result of annual CPS data supplementing the decennial Census data. The CPS is based on samples of about 60,000 workers. Males between 16 and 17 years old are only about 1 percent of the US workforce; those with at most $8^{\text {th }}$ grade educational attainment are less than 0.04 percent. So they make up only about 20 observations in a CPS sample. ${ }^{15}$

However, if one focuses on the observations based on Census data (i.e., the vertical lines in Figure 2 lining up with all but the 1996 Krueger points) it is clear that the implications for the post-1980 raw labor's share remain decidedly different. Our lowest, Census-based observation is 0.126 in 1979 . Notably, this is basically identical to Krueger's number of that year. However, our 1989 observation is nearly double that at 0.240 while Krueger's is nearly halved to 0.068 for that year.

Furthermore, as a robustness check we also calculate a raw labor's share based on female data for the same age and education levels (Figure 3). The average value is slightly bit lower than that of the baseline series $(0.182$ versus 0.220$)$ but is otherwise similar. Time trend estimations corresponding to (3) and (4) above yielded,

$$
L S_{F E M A L E}=0.227-0.002 * T
$$

and

$$
L S_{F E M A L E}=0.041+0.003 * T \text {. }
$$

The estimated trends are essentially identical to those of the baseline series and are both significant at the 1 percent level. (The series based on female data is also volatile as in the baseline case; see Table 1, column 3.)

Why might Krueger's (1999) measure of raw labor's share fall from the 1980s on while ours does not? Figure 4 demonstrates the results of an experiment designed to hint

\footnotetext{
${ }^{15}$ Mun Ho helpfully provided these numbers in discussion of the volatility of the series.
} 
at some answers. It plots (i) our baseline raw labor's share measure, (ii) a hypothetical labor's share calculated using males with marginally more education, i.e., some high school but no diploma, and (iii) a second hypothetical labor's share calculated using males with marginally more potential work experience, i.e., aged 18 to 24 years. The idea is to see how the average level and trends in raw labor's share change when we (hypothetically) use wage rates based on incremental increases, along two separate margins, in the human capital of the type of labor unit considered.

In case (ii) the hypothetical labor's share displays a mildly upward trend from 1949 to 1996 . A time trend regression for the entire sample period yields,

$$
L S_{S O M E_{-} H S}=0.186+0.001 * T,
$$

and the trend is significant at the 1 percent level. The mean is just above 0.20 while the minimum and maximum values, respectively, are around 0.18 and 0.25 . The volatility of the series is less than labor service's share with a relative standard deviation around 0.74 (Table 1; column 5). Surprisingly, it is consistently lower than our baseline measure until 1965. This begs the question of why labor with marginally more education consistently earned less than their uneducated counterparts. ${ }^{16}$ A sensible answer may be that they were often still in school and their earnings, to great extent, represent those from after school/weekend jobs. Therefore, they are not available as "full-time" labor units and had lower marginal products as such. More interesting, to us in any case, is that there is again no evidence of a fall is this hypothetical labor's share during the 1980s or 1990s. An implication of this is that the labor market essentially treats people with some high

\footnotetext{
${ }^{16}$ Note that this is the case for 1959 , based on Census data. In that year the (average) wage (in 1992 \$s) for 16 to 17 years old with $8^{\text {th }}$ grade education or less was $\$ 4.57$; for those with some high school education it was $\$ 3.18$.
} 
school education, but no diploma, as the productive equivalent of our concept of raw labor.

On the other hand, case (iii) presents us with a hypothetical labor's share that is both higher on average than the baseline (which we would expect) and is falling; not only from 1980 on but, indeed, across every single Census year-base observation (beginning around 0.40 in 1959 and falling to just over 0.25 in 1989). A time trend estimation for the complete sample yields,

$$
L S_{18 \_24}=0.410-0.003 * T,
$$

and the same estimation for 1970 through 1996 yields,

$$
L S_{18 \_24}=0.434-0.004 * T .
$$

These trends are both significant at the 1 percent level and, in contrast to the baseline case, the negative trend is more pronounced from $1970 \mathrm{on}$. The series' mean is about 0.335 and it is about twice as volatile of labor's services share (Table 1; column 4). This is the case based on a wage rate of marginally more experienced labor units (18 to 24 years of age). Taken with our baseline raw labor's share, case (iii) suggests that the relative marginal productivity of raw labor that has not fallen but, rather, the marginal productivity of experience (at least at low levels).

\section{Discussion and Conclusions}

Why is our measure of raw labor's share higher on average than Krueger's (1999) measure over the post-WWII period through 1996, and why does our measure not fall like Krueger's does from 1979 onward? 
As far as the average difference is concerned, one possibility is that, whereas Krueger does include both linear and squared terms of experience in his regressions, a squared term for schooling should also be included. If the slope of the earnings curve increases in educational-attainment, then the intercept may be underestimated. Another possibility is the estimated marginal productivity relationships in Krueger are correct but that the formal (and perhaps informal) minimum wage rate is higher than the estimated intercept. Using a full sample of experience-level and schooling-level individuals might yield a best fitting line that intercepts below that minimum wage rate. In other words, raw labor would earn a certain wage rate if it was paid its marginal product, but that wage rate is below some socially-acceptable minimum level.

As far as the downward trend in raw labor's share detected by Krueger (1999), a plausible interpretation is that the relative returns to raw labor have been falling but the socially-acceptable returns to raw labor have not fallen at pace. We do find a falling labor's share when considering marginally more experienced individuals. This may be because 18 to 24 year olds, in general, have not been paid at actual wage rates near the socially-acceptable minimum. Therefore, their relative actual compensation has been falling along with their relative returns. 


\section{References}

Acemoglu, Daron. "Technical Change, Inequality, and the Labor Market." Journal of Economic Literature, March 2002, 40 (1), pp. 7-72.

Fraumeni, Barbara. "The Measurement of Depreciation in the U.S. National Income and Product Accounts." Survey of Current Business, July 1997, 77 (7), pp. 7-23.

Goldin, Claudia and Katz, Lawernce F. "Decreasing (and then Increasing) Inequality in America: A Tale of Two Half-Centuries." in Welch (ed.) The Causes and Consequences of Increasing Income Inequality. Chicago, University of Chicago Press, 2001

Ho, Mun S. and Jorgenson, Dale W. "The Quality of the U.S. Work Force: 1948-95." Kennedy School of Government, Harvard University working paper, 1999.

Jorgenson, Dale W., Gollop, Frank M., and Fraumeni, Barbara, M. Productivity and U.S. Economic Growth. Cambridge, Harvard University Press, 1987.

Jorgeson, Dale W. and Stiroh, Kevin J. "Information Technology and Growth." American Economic Review, May 1999, 89 (2), pp. 109-115.

Katz, Lawrence F. and David H. Autor. "Changes in the Wage Structure and Earnings Inequality." inn Ashenfelter and Card (eds.) Handbook of Labor Economics, volume 3, North Holland, 1999.

Katz, Lawrence F. and Murphy, Kevin M. "Changes in Relative Wages, 1963-1987: Supply and Demand Factors." Quarterly Journal of Economics, February 1992, 107 (1), pp. 35-78.

Krueger, Alan B. "Measuring Labor's Share." American Economic Review, May 1999, 89 (2), pp. 45-51. 
Mincer, Jacob. Schooling, Earnings, and Experience. New York, Columbia University Press, 1974.

Solow, Robert M. "Technical Change and the Aggregate Production Function." Review of Economics and Statistics, August 1957, 39 (3), pp. 312-320.

Willis, Jonathan L. and Wroblewski, Julie. "What Happened to the Gains from Strong Productivity Growth?" Federal Reserve Bank of Kansas City Economic Review, First Quarter 2007, pp. 5-23. 


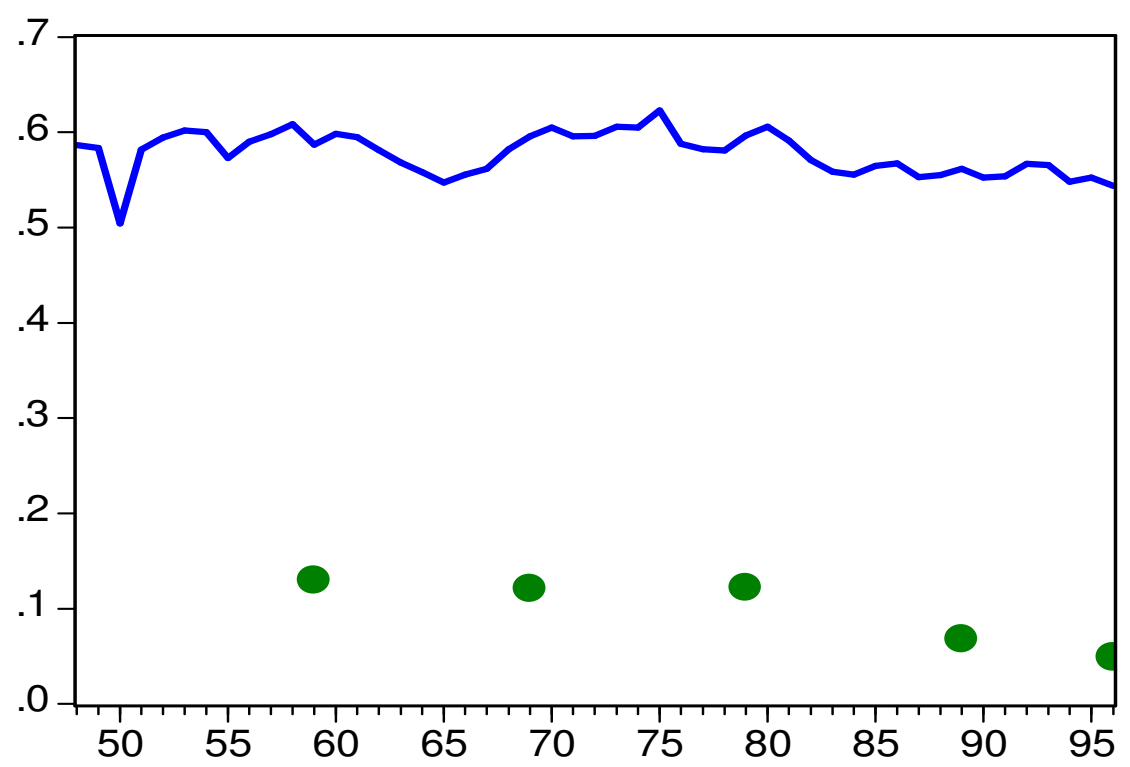

Figure 1 - Labor Service's SHARE AND KruEger (1999) Labor's SHARE

Notes: solid line is labor service's share; dots represent Krueger's measure.

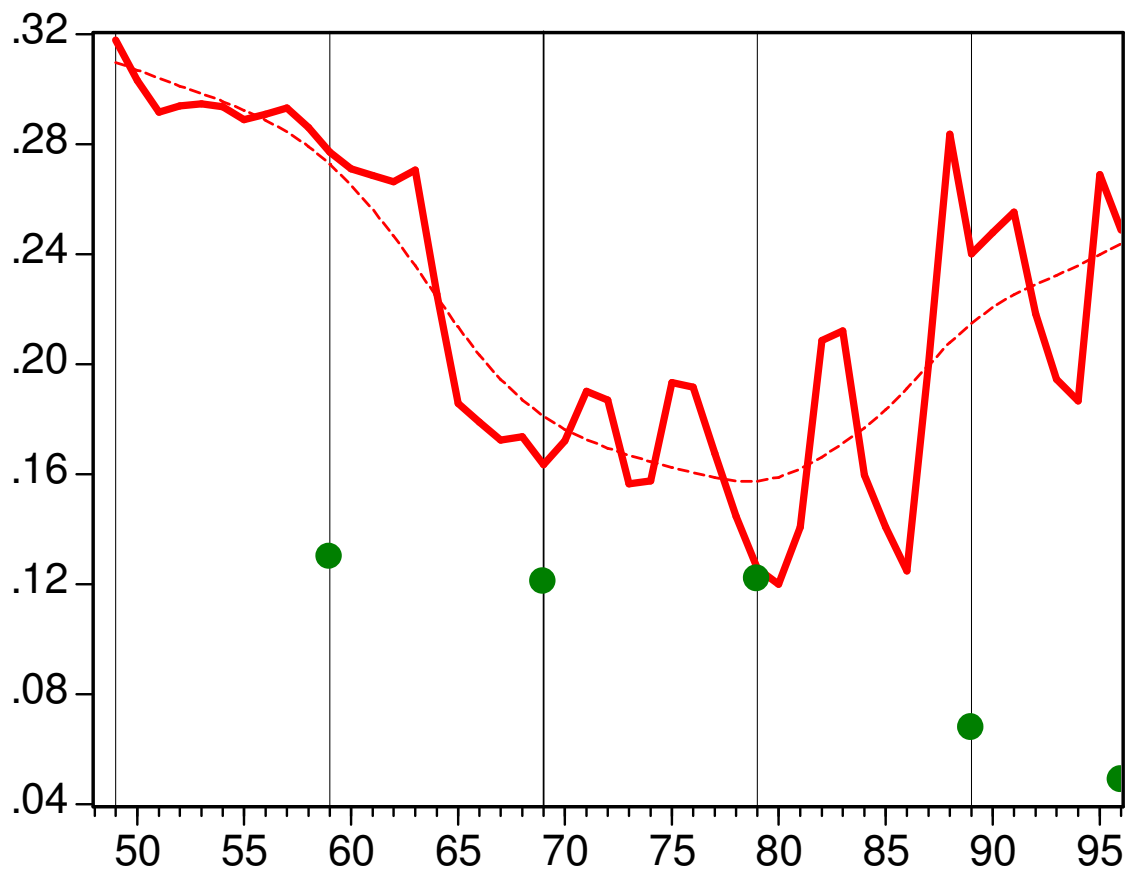

Figure 2 - (BASEline) RAW LABOR'S SHARE AND KRUEGER (1999) LABOR's SHARE

Notes: solid line is our raw labor's share. Dashed line represent HPfilter trend for smoothing parameter equal to 100. Dots represent Krueger's measure. Vertical lines correspond to observations based on Census data. 


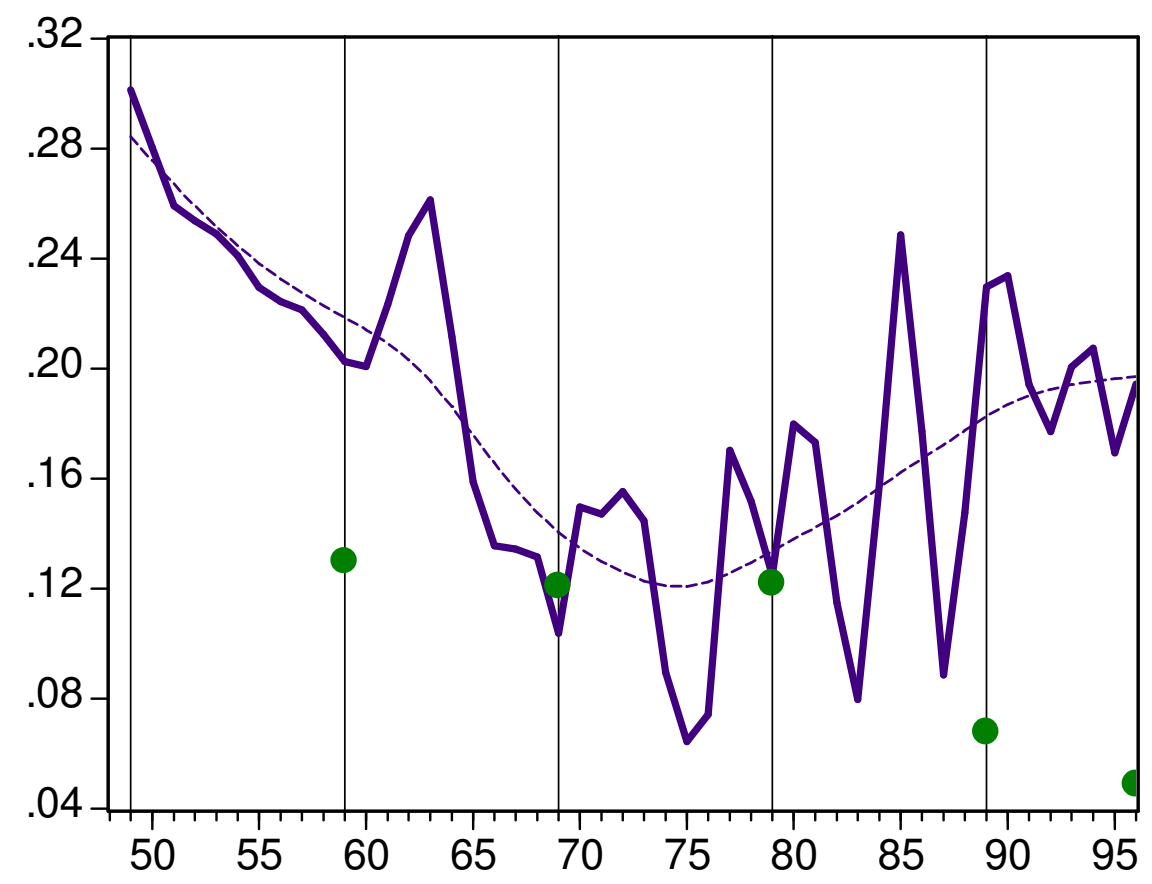

Figure 3 - (Female) Raw Labor's Share AND KRUeger (1999) Labor's Share

Notes: solid line is our raw labor's share. Dashed line represent HPfilter trend for smoothing parameter equal to 100 . Dots represent Krueger's measure. Vertical lines correspond to observations based on Census data. 


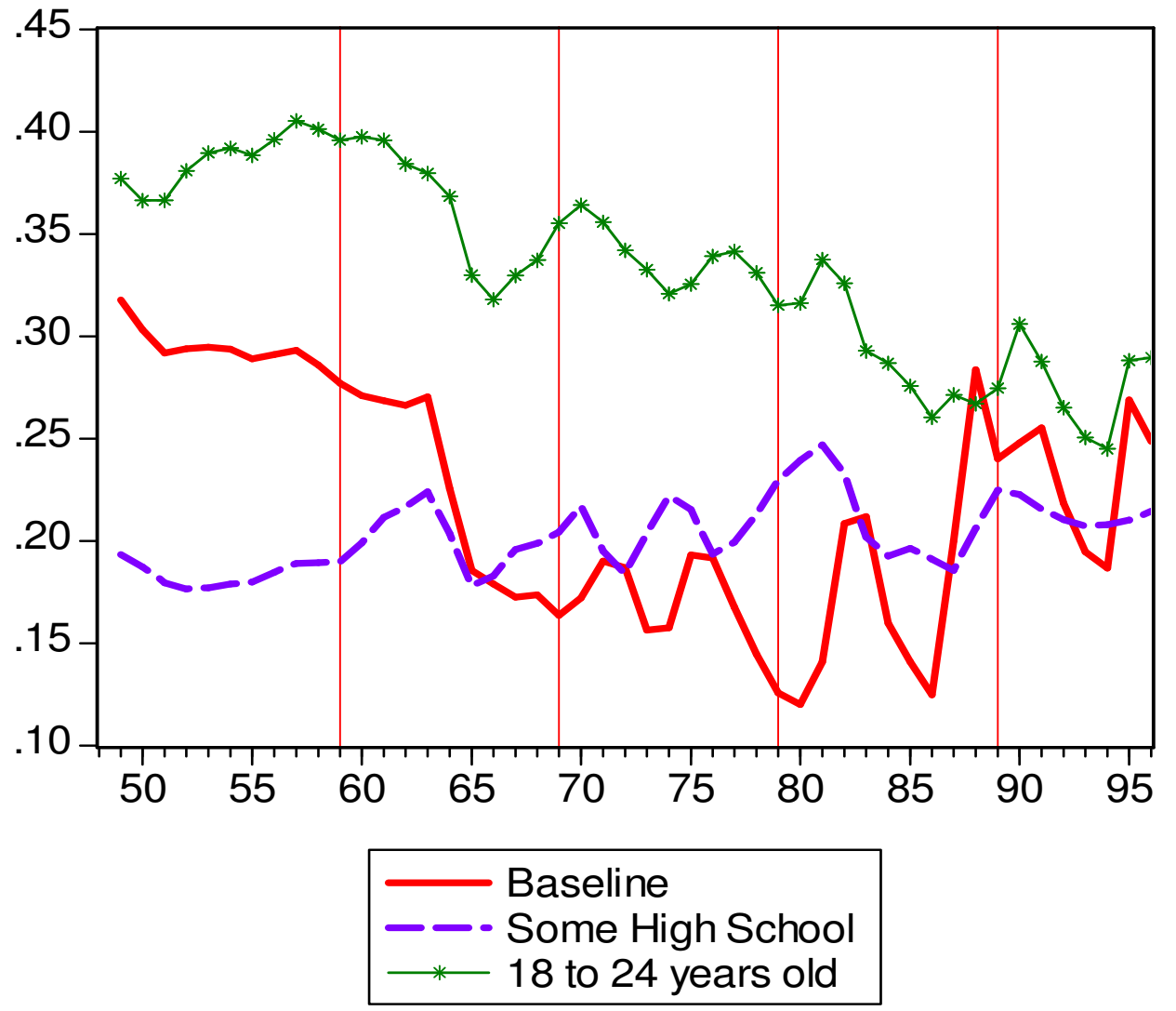

FIgURE 4 - RAW LABOR'S SHARE AND AdJUSTMENTS FOR MARginAl CHANGES IN POTENTIAL EXPERIENCE AND EDUCATIONAL ATTAINMENT

Notes: vertical lines correspond to observations based on Census data. 
Share

\begin{tabular}{lcccccc} 
Statistic & $\begin{array}{c}1 \\
\text { Labor }\end{array}$ & $\begin{array}{c}2 \\
\text { Raw } \\
\text { Service's }\end{array}$ & $\begin{array}{c}3 \\
\text { Raw }\end{array}$ & $\begin{array}{c}4 \\
\text { Raw } \\
(\text { Baseline) }\end{array}$ & $\begin{array}{c}5 \\
\text { Raw } \\
(\text { Female) }\end{array}$ & $\begin{array}{c}6 \\
\text { Average } \\
(18-24)\end{array}$ \\
\hline Mean & 0.5775 & 0.2197 & 0.1819 & 0.3347 & 0.2025 & 0.2523 \\
$\sigma$ & 0.0228 & 0.0582 & 0.0576 & 0.0464 & 0.0174 & 0.0285 \\
$\sigma / \sigma_{\text {Labor }}$ & 1.0000 & 2.5526 & 2.5263 & 2.0351 & 0.7362 & 1.2500 \\
$\begin{array}{l}\text { Service's } \\
\rho_{x, \text { Labor's }}\end{array}$ & 1.0000 & -0.1065 & -0.1690 & 0.4921 & 0.0704 & 0.2085 \\
Service's & & & & & & \\
\hline
\end{tabular}

Notes: $\sigma$ denotes standard deviation; $\rho$ denotes correlation. 